\title{
Investigar en Cuidados
}

\section{Research in Care}

\author{
Dra. M. Esperanza Rayón Valpuesta ${ }^{1}$ \\ ${ }^{1}$ Profesora Titular De La Facultad De Enfermería, Fisioterapia Y Podología - Universidad Complutense De Madrid, España.
}

No cabe duda de que en los últimos años, ha habido un enorme crecimiento de la investigación en Enfermería, especialmente a partir del desarrollo de programas de postgrado y sobre todo, a partir del acceso de las enfermeras al doctorado

Al mismo tiempo, sigue manteniéndose vigente lo que desde siempre, nos ha definido como profesión: la esencia de nuestro quehacer es el cuidado.

El contenido del cuidado, aquello que realizamos para cuidar, es lo que nos dota de identidad profesional, configura nuestro cuerpo de conocimientos y por lo tanto, determina el ámbito propio de investigación en nuestra profesión. Si queremos avanzar como profesión, si queremos generar conocimiento de Enfermería y en Enfermería, el camino es investigar en cuidados.

Pero, sin embargo, esta idea que parece tan obvia, no es fácil de llevar a cabo, por varias razones.

Una de ellas, por la difícil conceptualización del cuidado profesional: el cuidado enfermero no se puede delimitar, acotar: ¿qué es exactamente cuidar?. La respuesta obliga a manejar un concepto abierto, dinámico, flexible y por ello, cambiante. Por tanto, ¿qué es exactamente investigar en cuidados?. También resulta difícil responder de un modo unívoco a esta cuestión.

Otra razón, y como consecuencia de lo anterior, es que en muchas ocasiones, nuestra investigación bordea o incluso comparte espacios con otras disciplinas y con otros profesionales: la Educación, la Psicología, la Gestión, la Salud Pública...hasta el punto de llegar a preguntarnos hasta donde y en qué medida estamos haciendo investigación en Enfermería, es decir, en cuidados.

Investigar para nosotros, no es tarea fácil. Debemos construir nuestra investigación propia, definirla en cada paso que vayamos dando, tanto desde las Universidades como desde los centros asistenciales. Con criterios y propósitos claros.

Es por esto que resulta especialmente importante potenciar la investigación en el ámbito de la Atención Primaria de Salud y en la Atención Especializada (hospitalización), espacios ambos en los que de manera predominante, las enfermeras proporcionan cuidados. Es preciso investigar en cuidados que vayan a ser prescritos por enfermeras y evaluados por enfermeras. Buscar respuestas a preguntas de investigación que surjan de la práctica asistencial cotidiana, junto a la cabecera del paciente, que es nuestro lugar de trabajo por excelencia.

Esta investigación, la que surge del trabajo cotidiano de las enfermeras junto a sus pacientes, es la que realmente mejorará nuestra práctica profesional, la que la transformará. La que ampliará nuestros conocimientos y hará crecer la Enfermería como profesión. Y por encima de todo, la que ayudará a prestar un mejor servicio en la atención de salud a cada persona y a la sociedad. Es investigación en cuidados.

Correspondencia.

Dra. M. Esperanza Rayón Valpuesta

erayon@ucm.es 